The Market Impact of Leveraged and Inverse ETFs: Evidence from S\&P 500-Linked Products

\title{
Belisa Pang
}

Global Commerce Scholar at McIntire School of Commerce, University of Virginia

May 16, 2017

Acknowledgment: The author thanks Professor Michael Gallmeyer, Professor William Wilhelm, and Professor David Chapman at McIntire School of Commerce, University of Virginia for thoughtful discussions and suggestions. In particular, Professor Michael Gallmeyer was the faculty adviser for this thesis and the author is thankful for his continuous support. The author thanks Dean Christopher Wilcox-Elliott at McIntire School of Commerce, University of Virginia and the Global Commerce Scholars Program for providing technologies that facilitated the data analysis. 


\begin{abstract}
Due to valuable qualities such as lower fees, greater transparency, expanded access, and greater tax efficiency, Exchange Traded Funds (ETFs) have experienced a rapid growth in the recent years. Particularly, the leveraged and inverse ETFs are designed to track multiples of an underlying index's daily return through derivatives. This type of synthetic ETFs are often criticized for their potential to cause disproportionately large liquidity and volatility impact on the related markets. Prior literature showed that rebalancing demand resulted from the fixed leverage multiple is a key driver of this market impact. To support this argument, this thesis examines the leveraged and inverse ETFs linked to the S\&P 500 index for empirical evidence. Started from the framework introduced by Cheng and Madhavan (2009) and Ivanov and Lenkey (2014), this thesis found that the rebalancing demand caused significant trading volume increase across multiple days during the last trading hour, and may have contributed to the volatility of the underlying unleveraged index ETFs.
\end{abstract}

Key words: ETF, leveraged ETF, inverse ETF 


\section{Contents}

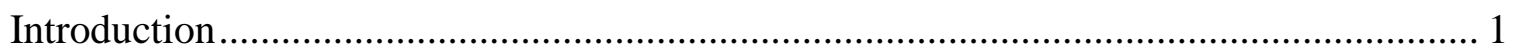

Construction of a Traditional Unleveraged ETF ………............................................. 3

Construction of a Leveraged or Inverse ETF........................................................... 4

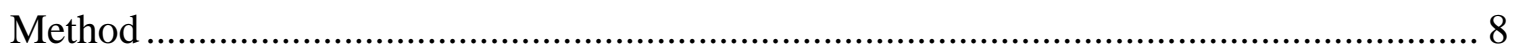

Estimate Leveraged and Inverse ETFs' Rebalancing Demand...................................... 9

Hypothesis: Rebalancing Demand Impact Model ................................................... 10

Empirical Analysis: ETFs Linked to the Standard \& Poor's 500 Index .......................... 12

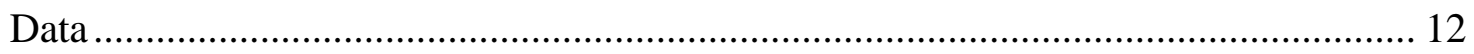

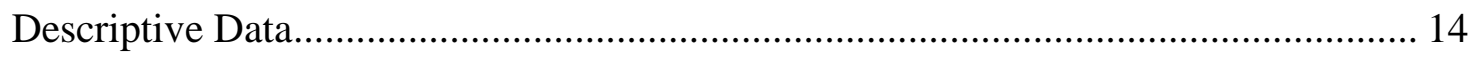

From Rebalancing Demand to Trading Volume........................................................ 15

From Rebalancing Demand to Daily Volatility ......................................................... 17

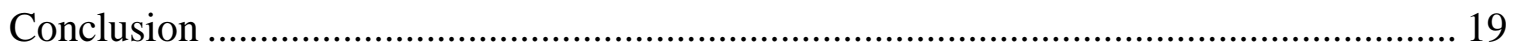

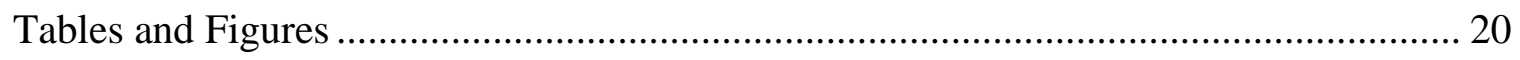

Table 1 Leveraged and Inverse Domestic Equity ETF/ETN Inceptions by Year..... 20

Table 2 Leveraged and Inverse ETFs Linked to S\&P 500 - Holdings ....................... 20

Table 3 Summary of ETFs Linked to the S\&P 500 Index ....................................... 20

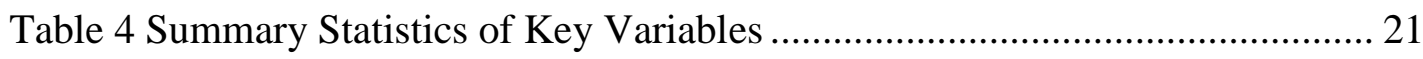

Table 5 Trading Volume Regressed on Rebalancing Demand ................................. 21 
Table 6 SPDR MOC Volume as Proportions of the Total Trading Volume of the

Day. 22

Table 7 SPDR MOC Volume Regressed on Rebalancing Demand ........................ 22

Table 8 Variance Proxy Regressed on Rebalancing Demand ................................ 23

Table 9 Variance Proxy Regressed on Rebalancing Demand - Deciles .................. 23

Table 10 Baseline Variance Decile Distribution Across Years ............................... 24

Figure 1 Leveraged and Inverse ETFs Market Share by Index .......................... 25

Figure 2 Rebalancing Exposure as Percentage of SPDR Market Cap .................... 25

Figure 3 SPDR MOC Trading as Proportion of Total Trading Volume of the Day. 26

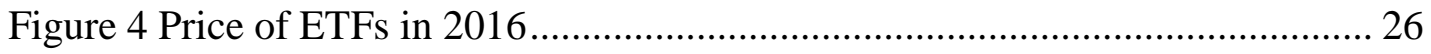

Figure 5 Capital Flows - Significant Impact on Rebalancing Demand ................... 27

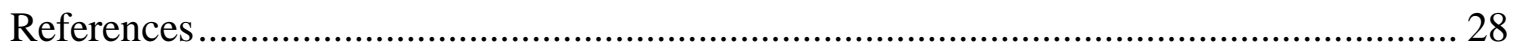




\section{Introduction}

Exchange Traded Funds (ETFs) have seen huge growth in assets under management (AUM) over the past decades. As of the end of Q1 2014, a total of 1,570 ETFs manage approximately $\$ 1.74$ trillion assets and represent between $25 \%$ and $40 \%$ of the total daily trading dollar volume on US exchanges. Similar to indexed mutual funds, ETFs typically hold a basket of securities to track an index, but ETFs are traded on an exchange like stocks. This allows investors to short sell and track their prices throughout the day. Other features of ETFs include lower fees, greater transparency, expanded access, and greater tax efficiency, as summarized by Hill and Hougan (2015). As ETFs continue to expand in size and trading volume, it has become increasingly important to understand their impact on the stock market.

The State Street SPDR S\&P 500 ETF (SPDR) is a textbook example of a traditional ETF. First listed in 1993, SPDR holds a portfolio of stocks that replicate the entire S\&P 500 and issues shares that can be bought and sold on exchanges. As SPDR shares are secured by its portfolio of stocks, no-arbitrage condition ensures that the ETF's price level matches the S\&P 500 index level. As Elton et al. (2002) and Hasbrouck (2003) summarized, ETFs like SPDR allow the investors to hold a diversified portfolio with a smaller price unit, providing an alternative to electronicallytraded index future contracts and index mutual funds. From a regulatory perspective, ETFs can be regulated as open-end companies or Unit Investment Trusts. Ang (2014) estimated that 90\% of the ETFs are registered as investment companies under the Investment Company Act of 1940 regulated by the SEC.

A large literature discussed how the introduction of ETFs changed the information flow in the stock market. One interesting debate is centered on how the demand from ETFs might affect the information revelation of stock prices related to the ETFs' underlying indices (i.e. if the 
demand of ETFs brought undesirable noise to the related stocks' price movements through liquidity and volatility shocks).

From one side, consistent with prior research on indexation by Barberis, Shleifer and Wurgler (2005), Da and Shive (2016) warned that comovements caused by ETFs might transmit non-fundamental shocks. When investors' demand on a certain ETF increases, no-arbitrage condition requires more shares to be supplied so that the demand will not raise the ETF's price too far from the underlying index level, and vice versa. To supply the new shares, the ETF needs to acquire more securities that replicate the underlying index. Most of the time, this involves a simultaneous purchase of all the index's constituents. If the purchase amount is large enough, it may create a simultaneous increase in constituent stocks' prices. Thus, if two stocks are included in the same index, the fluctuating demand on ETFs linked to this particular index may cause the two stocks to behave similarly (i.e. comovements) without a fundamental reason, especially when the two stocks have lower liquidity themselves.

Meanwhile, other researchers such as Glisten, Nallareddy, and Zou (2015) argued that ETF trading could improve the systematic component of informational efficiency. As expected from the CAPM and factor models, each individual stock's return should reflect the systematic risk across the market to some extent. As ETFs transmit movements in a broader market to the index's constituent stocks through the abovementioned mechanism, it may help adjust the price of stocks that originally lack an effective link to the market risk due to reasons such as low liquidity, short sale constraints, or analysts' coverage.

Additionally, Madhavan (2012) shows that changing trends such as exchange fragmentation and high-frequency trading might reveal new risks related to ETFs through an analysis of the Flash Crash in May 2010. While technological and regulatory changes are 
The Market Impact of Leveraged and Inverse ETFs: Evidence from S\&P 500-Linked Products 3

happening steadily on the trading floor, how they will interact with the preexisting ETF structures remains unclear.

\section{Construction of a Traditional Unleveraged ETF}

An ETF has a sponsoring firm (issuer) that creates and ministers the fund. The fund issues shares to Authorized Participants (APs) in an exchange of shares for stocks, which are typically the constituent stocks of the underlying index. Usually, a custodian bank will hold the stocks to ensure the collateralization.

Designated by the issuer, the Authorized Participants (APs) range from institutional investors to big banks, and they are mostly invisible to individual investors. Only the APs have direct access to the fund, which means that they have the option to create or redeem shares of ETFs in large units called "contracts" (e.g. 100 thousand shares) with shares of the constituent stocks. Other investors cannot create or redeem the shares with the fund, but they can buy or sell the shares with other investors including the APs. When the price of the ETFs derives from its underlying index, the APs have an arbitrage opportunity. If the price is too high, they can purchase the index's constituent stocks and create new shares with the fund, and then sell the ETF shares at a higher price to the secondary market. If the price is too low, they can redeem ETF shares and sell the stocks. Generally, more potential APs is better for the fund as the APs compete to gain a profit by erasing the ETF's tracking error as quickly as possible.

The advantage of having an AP between the fund and the secondary market is to save trading costs and taxes. The share creation and redemption of a traditional ETF are considered "inkind" for the APs and are exempted from capital gain taxes. Additionally, the trading in secondary market tends to mitigate the tracking error, allowing the fund itself to trade less frequently with 
the APs, which lowers the transaction costs. If the price is too high, more investors will choose to short the ETF as they anticipate that the APs will lower the price, causing the price to fall without actual intervention from the APs. The mechanism also works when the price is too low. Besides, if the investors want to trade for reasons other than arbitraging, they can settle among themselves without involving the fund. Creating a secondary market with APs provide significant benefit for the fund by reducing the amount of trading executed by the fund itself, as ICI Factbook (2016) estimated that on average $89 \%$ of the trading occurred in the secondary market.

However, the benefit from having APs requires a deep secondary market. When the market capitalization of the ETF is small, or when trading is infrequent, the benefit ceases and may lead to a higher expense ratio or tracking error.

\section{Construction of a Leveraged or Inverse ETF}

The leveraged and inverse ETFs are one type of synthetic ETFs. Unlike traditional ETFs such as SPDR, synthetic ETFs, including the majority of leveraged and inverse ETFs, mainly invest in derivatives such as index return swaps to engineer exposure to the desired level without holding a portfolio of stocks. The market structure is similar to a traditional ETF: the issuer designate one or several APs to initiate the fund, and the APs trade with other investors on a secondary market. However, the APs usually contribute cash in lieu of stocks so that the fund can use it as collateral to seek adequate exposure through derivatives. Different synthetic ETFs use different types of derivatives that give them the desired return when the underlying index moves.

The synthetic structure exists because it provides access to alternative indices that cannot be tracked through equities. However, it also makes the structure more complexed and opaque, creating problems such as risks related to the index return swap counterparties that may hurt 
unsophisticated investors. The use of other derivatives with an existing market, such as commodity options and future contracts, may create significant tension in the relatively illiquid derivative market. Due to the negative uncertainty related to synthetic ETFs, the SEC suspended the initiation of new synthetic ETFs in March 2010 (Ang, 2014), creating four years of quietness for the leveraged and inverse ETFs until the inception took off again in 2015.

The leveraged and inverse ETFs are synthetic ETFs that carry a combination of equity and derivatives to track multiples of a benchmark's daily performance. The multiple is called the fund's leverage factor. For example, the leverage factor of the largest leveraged fund linked to S\&P 500, the ProShares Ultra S\&P500 fund (ticker: SSO, $\$ 1.89$ billion assets under management, May 2017) is +2 , which means each dollar invested in SSO will give a daily return that is two times the daily return of the S\&P 500 index. If the index level increases 1\%, the price level of SSO will increase $2 \%$ on the same day.

Leveraged and inverse ETFs use swaps, futures contracts, and other derivative instruments to create leverage, while holding cash equivalents as collateral. For example, to achieve a leverage ratio of +2 , SSO entered one future contract and eight swap contracts (with seven major banks) linked to the S\&P 500, besides holding about 28\% of the asset in cash (Proshares, May 2017). The portfolio may not necessarily include stocks, even if the ETF is linked to equity indices. As summarized by Table 2, among S\&P 500 linked ETFs approximately $89 \%$ of the aggregated leverage exposure was achieved through derivatives, primarily variable quantity index return swaps. A variable quantity swap contract allows the fund to adjust the size of the swap at the end of the day without entering a new contract.

Leveraged and inverse ETFs have a relatively large trading volume due to structural tracking error favoring a shorter holding period, as supported by evidence from Charupat and Miu 
(2011). These ETFs are designed based on daily return, which causes the compounded return over a longer period to deviate from that of a fully leveraged index. For example, if the index moves from 1 to 0.9 to 1.2 over two days, a leveraged ETF with multiple +2 will moves from 1 to 0.8 to 1.33. However, if the investor bought one share of an unleveraged ETF based on the same index and borrowed another share on margin to create a full +2 leverage ratio, the value at the end of the second day would be $1+2 \times(1.2-1)=1.4$ instead of 1.33 . This tracking error often happens in a way that hurts the investors, especially when the volatility is high (Cheng and Madhavan, 2009).

In order to keep a fixed leverage ratio on a daily basis, rebalancing is often required when stock price movement changes the leverage or inverse ETF's assets under management (AUM). The leverage exposure, or the exposure to underlying index refers to the dollar amount required to achieve the desired return, if only invested in the plain-vanilla index fund without leverage. For example, $\$ 1$ of SSO (leverage multiple +2 ) requires an index exposure of $\$ 2$, because only by investing \$2 in the underlying index can we achieve twice the index return of that day. Unleveraged ETFs with value-weighted indices do not need to rebalance, because the changes in their AUM, which is exactly the amount of exposure they require, match perfectly with the index movements. However, in the case of leveraged ETFs, when the underlying index rises, the required exposure increases more than the increase in the value of the assets under management, requiring the fund to take on more leverage through swaps. The swap counterparties need to hedge the risk through either a basket of the index's constituent stocks or unleveraged ETFs like SPDR, creating more demand to the underlying index. It is also true for inverse ETFs, as the required exposure falls slower than the decrease in the value of AUM when the underlying index increases. In other words, the equity demand from rebalancing is positively correlated with the stock return (Cheng and Madhavan, 2009. See Method section for more rigorous proof), and the demand from leveraged 
ETFs does not cancel out the demand from inverse ETFs but adds up in the same direction. Buying the winning stocks and selling the losing stocks as a result from this positive correlation, leveraged and inverse ETFs may have potentially increased the volatility of the market. My thesis found empirical evidence that the rebalancing demand has caused trading during the last trading hour and might have increased the daily volatility in the S\&P 500 market segment.

Additionally, Ivanov and Lenkey (2014) pointed out that capital flows due to share redemption and creation from the APs should be included in the analysis. Capital flows refer to the transactions between APs and the fund, when the APs put more money into the fund (inflows) or withdraw money from the fund (outflows). Generally, this will happen when the demand of the ETF creates profitable tracking errors for the APs, as they can create more shares and sell them at a high price, or they can redeem money with shares bought at a low price. Capital outflows decrease the fund's assets, which in turn decreases the demand for leverage. In contrast, capital inflows increase the fund's assets, which will increase the required leverage. Thus, if outflows happen when the index rises, or if inflows happen when the index drops, the capital flows can help to reduce the rebalancing demand. Ivanov and Lenkey (2014) concluded that historically capital flows tended to mitigate the rebalancing demand. Consistent with their results, I found that in S\&P 500 linked products capital flows happened frequently and often counteracted the rebalancing demand. With a longer time horizon and a narrower set of ETFs compared to their study, this thesis' data suggested that capital flows occurred on approximately $36 \%$ of the trading days for each individual ETF. In this thesis' sample, capital flows occurred on $85 \%$ of the trading days and on average, $56 \%$ of the capital flows happened in the direction that would reduce the demand.

Moreover, the synthetic structure of leveraged and inverse ETFs might amplify the market impact from the rebalancing demand. In other words, a one-share demand on related stocks or 
unleveraged ETFs may cause more effect if it comes from a leveraged or inverse ETF, rather than an average investor. This is primarily due to the complexity of the synthetic structure and the fact that the ETFs always adjust the swaps at the end of the day, which may invite speculative trading or other related trading activities. The synthetic structure suggests that when considering the market impact of rebalancing demand, we need to consider the behaviors of the swap counterparties in addition to the fund itself, as the use of swaps that are quantity-variable shifts the hedging need from the ETF to the swap counterparties (i.e. a broker-dealer firm). For example, as Bessembinder (2015) summarized, a broker dealer can choose from a variety of alternatives to offset the effects on the floating end of the swaps, including the purchase of a highly related ETF. Each alternative may lead to different effects on the market. Overall, the market impact from rebalancing activities depends on (1) the type and the amount of contracts the ETF enters (2) how much risk the derivative counterparties want to mitigate, and (3) the way the counterparties mitigate the risks. When settled through a synthetic structure, the rebalancing demand involves many other factors in the trading ecosystem besides the leverage factor. My thesis found evidence that a large portion of the demand was settled on the second day, and the total trading added up to approximately twice the underlying demand.

\section{Method}

The base framework for this thesis was introduced by Cheng and Madhavan (2009) and Ivanov and Lenkey (2014). This thesis adopted their way of calculating rebalancing demand and attempted to show the significance of the market impact by estimating several parameters in the framework. 


\section{Estimate Leveraged and Inverse ETF'’ Rebalancing Demand}

Consistent with Cheng and Madhavan (2009), this thesis calculated the rebalancing demand as a function of the leverage factor, the stock return, and assets under management (AUM). At the beginning of the day, the fund has leveraged exposure

$$
E_{t}=A_{t} m
$$

where $m$ stands for the leverage factor, and $A_{t}$ stands for the AUM at the beginning of day $t$. During the day, the index has return $r_{t}$. Due to leverage, the leverage exposure without rebalancing at the end of the day becomes

$$
E_{t+1}^{\prime}=A_{t} m\left(1+r_{t}\right) .
$$

However, the required exposure with $\mathrm{AUM}$ at the end of the day, $A_{t+1}$, was

$$
E_{t+1}=A_{t+1} m
$$

which gives the rebalancing demand

$$
\Delta t=E_{t+1}-E^{\prime}{ }_{t+1}=A_{t+1} m-A_{t} m\left(1+r_{t}\right)
$$

with respect to the leverage factor $m$, the stock return $r_{t}$, the AUM at the beginning of the day $A_{t}={\text { Share } \text { Price }_{t} \times \text { Shares Outstanding }}_{t}$, and the AUM at the end of day $A_{t+1}$ calculated similarly as $A_{t}$.

As shown by Ivanov and Lenkey (2014), there are two causes of rebalancing demand: the index return and the capital flows. Because this thesis does not distinguish the two different sources, Equation (1) was sufficient to calculate the rebalancing demand. Nevertheless, it is worth noting that the model can be expanded to show the different parts of rebalancing demand. In particular, for a leveraged or inverse ETF with leverage factor $m$,

$$
\text { Share } \text { Price }_{t+1}=\text { Share Price }_{t} \times\left(1+m r_{t}\right)
$$

and thus, 


$$
A_{t+1}=\text { Shares Outstanding } \text { St+1 }_{t} \times \text { Share Price }_{t} \times\left(1+m r_{t}\right)=A_{t} \frac{\text { Shares Outstanding }_{t+1}}{\text { Shares Outstanding }_{t}}\left(1+m r_{t}\right) \text {. }
$$

If we define the change in shares outstanding as

$$
f_{t}=\frac{\text { Shares Outstanding }}{t+1}-1
$$

then by Equation (1)

$$
\Delta t=A_{t}\left(f_{t}+1\right)\left(1+m r_{t}\right)-A_{t} m\left(1+r_{t}\right)=A_{t} m\left[(m-1) r_{t}+f_{t}+f_{t} m r_{t}\right]
$$

In this way, the model splits the rebalancing demand into (1) the demand from index return $A_{t} m(m-1) r_{t},(1)$ the demand from capital flows $A_{t} m f_{t}$, and (3) the demand from the interaction of index return and capital flows $A_{t} m f_{t} m r_{t}$. As stated in Introduction, in absence of capital flows, the rebalancing demand is always positively correlated to index return because $m(m-1) \geq 0$ for all leveraged and inverse ETFs ( $m-1$ and $m$ always have the same sign).

\section{Hypothesis: Rebalancing Demand Impact Model}

The thesis looks into the impact of the rebalancing demand on unleveraged ETFs sharing the same underlying index with the leveraged or inverse ETFs. Specifically, the thesis looks into products linked to the S\&P 500 index as an example. To capture the impact, the thesis first developed a theoretic model, and then estimated several parameters through different regression technics to show the timing and the magnitude of the impact.

The thesis assumed that all rebalancing demand was settled through unleveraged ETFs linked to the same index. Indeed, it is highly possible that some rebalancing demand was settled via instruments other than the corresponding unleveraged ETFs, as over-the-counter alternatives are usually available. However, as a primary way to gain exposure to the U.S. large-cap equities, the unleveraged index ETFs are a good proxy of the trading universe and their data is relatively easy to obtain. 
Adapted from Cheng and Madhavan (2009), the impact model of the rebalancing demand is

$$
\text { Impact }=q_{t}+\lambda[\varphi \Delta t+(1-\varphi) \Delta t-1]+\omega_{t}
$$

where the left side of the equation, Impact can be different liquidity or volatility measures of the underlying unleveraged ETFs, such as trading volume or daily volatility proxies. The model connects the change in the measure of interest to the contemporaneous and prior-day rebalancing demand ( $\Delta t$ and $\Delta t-1$ respectively) assuming that a certain percentage $(1-\varphi)$ of the demand is transferred to the next day. The impact factor $\lambda$ measures the magnitude of the impact on the focal volatility or liquidity measure. The stochastic factor $\omega$ captures unpredictable and irrelevant noise impact. The impact from other market participants are summarized by $q$, which is an omitted variable in the regressions.

If there is no impact from the rebalancing demand, the impact factor $\lambda$ should be zero. Similarly, if no demand is left to the second day, the parameter $\varphi$ would be 1 . Thus, the impact factor $\lambda$ captures the magnitude of the impact, while the parameter $\varphi$ captures the timing of the impact. When regressing a measure of liquidity or volatility of the underlying unleveraged ETFs on the independent variables on the right side of Equation (2) (contemporaneous rebalancing demand $\Delta t$ and prior-day rebalancing demand $\Delta t-1)$, the regression coefficient of $\Delta t$ equals $\lambda \times \varphi$, and the regression coefficient of $\Delta t-1$ equals $\lambda \times(1-\varphi)$. Thus, $\lambda$ is the sum of the two coefficients, and $\varphi$ is the proportion of the contemporaneous coefficient to the sum of the two coefficients. In this thesis, the value of $\lambda \times \varphi$ is called contemporaneous effect, and the value of $\lambda \times(1-\varphi)$ is called prior-day effect. 
The Market Impact of Leveraged and Inverse ETFs: Evidence from S\&P 500-Linked Products 12

\section{Empirical Analysis: ETFs Linked to the Standard \& Poor's 500 Index}

This paper is aimed at linking the estimated rebalancing demand to the trading volume and the volatility of the unleveraged ETFs with the same underlying index. Intuitively, the demand for additional leverage will increase the demand for the underlying securities due to hedging needs. However, it is unclear how this will impact the liquidity and the volatility, as the synthetic structure complicates the hedging process. The two hypotheses are: (i) the rebalancing demand has a significant impact on the related unleveraged ETFs with a significant positive impact factor $\lambda$ in Equation (2) applied to both trading volume and volatility; (ii) the impact extends to multiple days with a significant positive parameter $\varphi<1$. Additionally we expect the trading volume effect to be stronger during the last trading hour of the day, and the volatility impact tends to be larger when the volatility is already high. This thesis looked into S\&P 500-linked products for evidence.

\section{Data}

I used Bloomberg to identify the historic pool of U.S. ETFs that track multiples of the daily performance of domestic equity indices. The list included 147 ETFs and 33 ETNs, out of which 48 no longer existed. As of April 1, 2017, the total market capitalization of this sector summed up to 27.5 billion U.S. dollars. Sixteen leveraged and inverse ETF/ETNs with approximately 8 billion dollars under management track the S\&P 500 index. Another 3.5 billion dollars track the Nasdaq 100. Due to the availability of daily trading data, I excluded four ETNs with a trivial $\$ 8$ million market capitalization from my study and focused on the remaining twelve ETFs tracking multiples of the S\&P 500 .

This segment is highly concentrated as ETFs issued by ProShares account for $\$ 6.5$ billion out of the \$8-billion market. Direxion contributed another \$1 billion. The segment is also small, 
as the largest passive index fund, the SPDR S\&P 500 ETF Trust, dwarfed its leveraged peers with \$240 billion assets under management. However, after adjusting for leverage, the actual exposure to the U.S. large cap equities was equivalent to about $10 \%$ to $20 \%$ of the AUM of the SPDR. In the peak years 2009 and 2010 the number was approximately $30 \%$.

To obtain daily and intraday trading data, I first retrieved the historic tickers used by each fund from the Center for Research in Security Prices (CRSP). Then, I retrieved the closing price, shares outstanding, trading volume, and market capitalization from Bloomberg, which also provided categorical data such as the underlying indices and leverage factors. Some ETFs are linked to the total return version of the S\&P 500 index (i.e. another index based on S\&P 500 index assuming no dividends distribution), but I treated all ETFs as if they were linked to the plainvanilla S\&P 500 index. In addition, I adjusted the price levels and shares outstanding to account for normal cash dividends, splits, and consolidations.

I used a similar method to obtain data for the unleveraged ETFs, namely the State Street SPDR ETF Trust (SPDR), the Vanguard S\&P 500 ETF (VOO), and the iShares Core S\&P 500 ETF (IVV). As of April 2017, the price level of three ETFs was approximately one tenth of the S\&P 500 index level. Because VOO executed a one-for-two inverse split on October 24, 2013, I adjusted the shares outstanding of VOO where appropriate. I obtained the daily index level of S\&P 500 from CRSP.

The daily data started from June 2006, when ProShares created the first eight leveraged ETFs tracking domestic equities. The intraday data started later on February 2008 due to data availability constraint. Unless otherwise noted, I used data up to December 2016. Bloomberg recorded 2,652 trading days during this period. For the regressions, I used calendar days excluding weekends as the timeline as it best captured the time series properties. Using trading days would 
introduce additional noise due to the mismatch between the statistical lagged terms and the actual weekdays, but it did not substantially change the results. The non-trading weekdays were considered missing data and thus, they were excluded from the regressions. Besides, I excluded inception days when I calculated the rebalancing demand. A total of 2,651 trading days were recorded during the time span (June 21, 2006 to December 30, 2016) with 19,830 daily observations of ETFs and 2,651 daily observations of the S\&P 500 index.

\section{Descriptive Data}

For the purpose of this study, I focused on the ETFs tracking multiples of the S\&P 500 index. In this segment, the average absolute amount of daily rebalancing demand was $\$ 229$ million over the period. In real value, the average was positive $\$ 1.4$ million with a positively skewed distribution and kurtosis over 11 . The standard deviation was over $\$ 350$ million and was clearly time variant. For example, in the aftermath of the financial crisis, the rebalancing demand was more than $\$ 1$ billion on at least 20 trading days from October 2008 to June 2009 driven by the ProShares twin SDS $(-2 x)$ and SSO $(2 x)$. The two funds saw a dramatic increase in assets under management prior to the crisis from less than $\$ 350$ million at the beginning of 2007 to over $\$ 3$ billion each. During the same period, SPDR's average value traded per day was about $\$ 30$ billion according to Bloomberg.

Compared to passive index funds, the rebalancing demand might seem too small to cause any problems. However, it worth noting that the time-variant demand tends to be more volatile when the underlying index is more volatile. In fact, in the absence of capital flows, the volatility of the demand would be $m(m-1) \times$ index volatility, based on (1). Besides, empirical evidence suggests that most of the demand is settled at the end of the day, creating large trading flows over 
a short period of time that might further amplify the impact. As a result, the rebalancing demand could potentially increase the possibility of extreme volatility in the underlying indexed funds, despite its relatively small dollar amount.

\section{From Rebalancing Demand to Trading Volume}

To analyze the liquidity impact of the rebalancing demand, I first looked into the trading volume of the underlying index funds. I calculated the aggregated trading volume of the three available passive S\&P 500 index ETFs SPDR, VOO, and IVV after the abovementioned adjustments to VOO. Indeed, it is highly possible that part of the demand was settled via other instruments, such as the over-the-counter alternatives. Besides, issuers and other players in the transaction might choose to absorb part of the risk. However, as a primary way to gain exposure to the U.S. large-cap equities, the index funds are a good proxy of the trading universe and their data is relatively easy to obtain.

Ordinary linear regression reveals that contemporaneous rebalancing demand has a 1 to 1.4 effect on the trading volume of the underlying index $\operatorname{ETFs}(\lambda \times \varphi=1.4)$, controlled for same-day index return and past trading volume. In other words, the demand to long or short one share of unleveraged ETFs would cause over a one-share increase in the aggregated trading volume. For this analysis, I used the absolute amount for both rebalancing demand and daily return, which makes a logical assumption that the demand to long one share or short one share should increase the trading volume in the same way.

The index return is included in the regression because it is well known that the rebalancing demand tends to increase with the index return and so does the trading volume, which might cause a spurious linear relationship if the index return was omitted. Besides using OLS, I used another 
method to account for this effect: I first regressed rebalancing demand on the index return, and then used the estimated residuals as an instrumental variable for the main regression. In this way, the residuals are uncorrelated with the return by construction, and the regression coefficients are better estimated. The contemporaneous effect remains similar at 1.3, and the prior-day rebalancing demand has a significant negative effect. In contract, the two-day-prior rebalancing demand has a positive regression coefficient of 2.0. After three days, the effect was no longer significant.

The unexpected negative prior-day effect is largely due to noise from earlier trading during the day, as most trading activities from the ETFs happen in the last hour before the market closes. To analyze this effect, I obtained intraday trading data of the SPDR Trust from January 2008 to December 2016 and repeated the process on the trading volume of the last hour. In consistency with the daily data, the contemporaneous effect remains approximately 1.10 . Nevertheless, the prior-day effect now has the correct sign (positive 0.81 ) and there is no significant effect after 2 days. With the regression coefficients, it is easy to induce the parameters in Equation (2): trading volume impact factor $\lambda=1.10+.81=1.91$ with only $\varphi=\frac{1.10}{1.91}=57.6 \%$ of the impact settled on the same day, as expected from the hypotheses.

The Market on Close (MOC) trading accounts for approximately $20 \%$ of the daily trading volume of SPDR from 2008 to 2016. I split the hour into four fifteen-minute periods and repeated the regression on each interval. While the contemporaneous effect was approximately evenly distributed across the four intervals, the prior-day effect varied significantly. In particular, the effect was the highest for the interval with the most trade during the last hour of the day, with prior day effect as high as .55 (corresponding to $58 \%$ of the whole hour), together with a higher contemporaneous effect than any fixed time interval, despite that the period had higher total trading volume than other periods to begin with. This is consistent with the argument that rebalancing 
demand is causing significant MOC trading and tends to happen when the trading volume is already high. Due to limited data availability, I could not extend my analysis to prior to 2008 .

To estimate a causal effect, I conducted Granger Causality tests on the variables. With two lag terms, contemporaneous rebalancing demand Granger caused trading volume. The reverse was rejected for the intraday data, but not the daily data. Thus, consistent with the regressions, the evidence is stronger when using market-on-close trading data.

\section{From Rebalancing Demand to Daily Volatility}

The next step is to test if the rebalancing demand increases the daily volatility of the underlying index. A commonly used proxy for daily return volatility is simply the squared daily return, since the mean daily return is very near zero and is hard to estimate precisely.

Because the squared return and the rebalancing demand have different units, I divided the squared return by its standard deviation to test the regression's economic significance. After controlling for daily return and the non-stationarity of the variance proxy, the regression suggested that approximately $\$ 1.9$ billion rebalancing demand would cause the variance to move by one standard deviation. Equivalently, when rebalancing demand moves by one standard deviation (\$351 million), the index volatility would move by .19 standard deviation in the same direction. For example, if we define extreme volatility as one that falls outside the $95 \%$ confidence intervals (the 5\% most extreme situations), then conservatively estimation shows that a $\$ 351$ million increase in rebalancing demand will double the possibility to nearly $10 \%$.

As the case of trading volume, I controlled for the positive correlation between the rebalancing demand and the index return by adding a control variable to the regression. I also used the same two-step method by regressing rebalancing demand on daily return, and then regress 
squared return on the residuals. This method also allowed me to estimate the effect of the priorday rebalancing demand. The regression coefficients did not change much as the contemporaneous effect moved from .19 to .16 , and the prior-day effect was .10 . Daily return was no longer significant in the regression, which is logical since we should not observe a linear relationship between the return and the return's quadratic form. From the regression coefficients we can estimate the parameters in Equation (2) with variance as the dependent variable: variance impact factor $\lambda=.16+.10=.26$ and $\varphi=\frac{.16}{.26}=61.5 \%$ of the impact was settled on the same day, with expected significance and signs from the hypotheses.

To test the causality, I used the same Granger Causality test as for trading volume. Contemporaneous rebalancing demand Granger caused differenced squared return, but the reverse is not true at any significance level. However, one problem with the test was that the vector autoregression (VAR) model used for the test had serially correlated residuals that could not be eliminated by differencing or expanding time series orders. Nevertheless, there was not enough evidence to reject the estimated model.

Additionally we want to see if the volatility impact increases when the baseline volatility increases due to factors other than rebalancing demand. In other words, we want to know if the volatility impact is larger when the underlying unleveraged ETFs are already very volatile, because extra volatility during highly volatile periods may be more painful and may cause extreme condition to happen more frequently. Thus, I split the daily observations into deciles based on the estimated baseline variance proxy (i.e. variance without the impact from rebalancing demand), and repeated the regression across deciles. To get the baseline volatility, I used the regression results from the abovementioned instrumental variable regression on daily variance proxy, and subtracted the estimated variance caused by rebalancing demand from the actual variance proxy. 
The result supports the hypothesis that the impact tends to be larger when the baseline volatility is already high. Both contemporaneous and prior-day effects are positively correlated with the decile number, indicating a stronger variance impact factor when the baseline variance is higher. The highest decile (i.e. most volatile) have strikingly high regression coefficients, indicating a much higher impact factor than other deciles. It is worth noting that the volatility of the underlying unleveraged ETFs is time-variant, as $75 \%$ of observations in the highest deciles happened during the aftermaths of the financial crisis (2008 to 2011).

\section{Conclusion}

While the market capitalization is still small for the leveraged and inverse ETFs, the rebalancing activities at the end of the day can potentially increase the possibility of extreme volatility to happen in the market. Empirical evidence from ETFs tracking the S\&P 500 index supports the hypothesis that the rebalancing demand caused a net increase in the underlying passive ETFs' trading volume, especially at the end of the trading day. Besides, we found evidence that the rebalancing demand has a positive correlation with the daily volatility of the index, even after controlling other factors such as the daily return. In particular, the effect tends to be stronger when the underlying unleveraged ETFs' volatility caused by other factors is already high. To better understand the magnitude of the effect, a Monte Carlos simulation may be more suitable than solving the distribution by induction.

While trading volume may indicate the level of liquidity to some extent, it is not a very effective liquidity proxy. To make a conclusion on the liquidity impact, better measures (e.g. the bid-ask spread) are required. Similarly, another proxy for intraday volatility is the high-low spread over a very short period time (e.g. fifteen minutes). 


\section{Tables and Figures}

\section{Table 1 Leveraged and Inverse Domestic Equity ETF/ETN Inceptions by Year}

\begin{tabular}{lccccccccccc}
\hline & 2006 & 2007 & 2008 & 2009 & 2010 & 2011 & 2012 & 2013 & 2014 & 2015 & 2016 \\
\hline \hline Number of ETFs & 12 & 46 & 22 & 10 & 20 & 3 & 2 & 2 & 3 & 23 & 4 \\
Number of ETNs & & & & 1 & 8 & 4 & 3 & 3 & 5 & 5 & 4 \\
\hline Total & 12 & 46 & 22 & 11 & 28 & 7 & 5 & 5 & 8 & 28 & 8
\end{tabular}

Table 2 Leveraged and Inverse ETFs Linked to S\&P 500 - Holdings

\begin{tabular}{|c|c|c|c|c|c|c|c|c|c|c|}
\hline \multirow{2}{*}{$\begin{array}{l}\text { Issuer } \\
\text { Ticker } \\
\end{array}$} & \multicolumn{5}{|c|}{ ProShares } & \multicolumn{5}{|c|}{ Direxion } \\
\hline & UPRO & SDS & $\mathrm{SH}$ & SPXU & SSO & SPDN & SPXS & SPXL & SPUU & LLSP \\
\hline Derivatives $^{1}$ & $\$ 2,362.8$ & (\$ $\$(2,810.9)$ & $\$(1,994.4)$ & (\$ $(2,103.4)$ & \$ \$2,412.7 & (38.0) & $\$(1,261.5)$ & \$ \$ 1,498.4 & 5.1 & 2.3 \\
\hline$\%$ Leverage & $90 \%$ & $100 \%$ & $100 \%$ & $100 \%$ & $64 \%$ & $100 \%$ & $99 \%$ & $88 \%$ & $72 \%$ & $24 \%$ \\
\hline $\operatorname{Cash}^{2}$ & 618.6 & $\$ 1,405.2$ & \$ $1,994.4$ & 701.0 & 533.8 & 41.2 & 451.1 & 372.7 & 1.4 & 0.4 \\
\hline$\%$ Asset & $71 \%$ & $100 \%$ & $100 \%$ & $100 \%$ & $28 \%$ & $108 \%$ & $106 \%$ & $66 \%$ & $38 \%$ & $5 \%$ \\
\hline Stock $^{3}$ & 253.9 & - & - & - & $\$ 1,345.3$ & - & (15.6) & 198.2 & 2.0 & 7.4 \\
\hline$\%$ Asset & $29 \%$ & - & - & - & $71 \%$ & - & $-4 \%$ & $35 \%$ & $57 \%$ & $95 \%$ \\
\hline$\%$ Leverage & $10 \%$ & - & - & - & $36 \%$ & - & $1 \%$ & $12 \%$ & $28 \%$ & $76 \%$ \\
\hline Total Assets & 877.0 & $\$ 1,406.1$ & \$ $1,994.9$ & 698.8 & $\$ 1,887.9$ & 38.0 & 425.8 & 565.3 & 3.5 & 7.8 \\
\hline Total Exposure & $\$ 2,616.7$ & $\$(2,810.9)$ & $\$(1,994.4)$ & $\$(2,103.4)$ & $\$ 3,758.0$ & $(38.0)$ & $\$(1,277.1)$ & $\$ 1,696.7$ & 7.1 & 9.8 \\
\hline Leverage Multiple & 3 & -2 & -1 & -3 & -2 & -1 & -3 & 3 & 2 & 1.25 \\
\hline
\end{tabular}

\section{Table 3 Summary of ETFs Linked to the S\&P 500 Index}

\begin{tabular}{|c|c|c|c|c|c|c|c|c|c|}
\hline Ticker & Leverage & Fund Type & Inception & $\begin{array}{c}\text { Market } \\
\text { Capitalization (\$m) }\end{array}$ & Shares $(\mathrm{m})$ & $\begin{array}{c}\text { Trading } \\
\text { Volume (m) }\end{array}$ & & Price & $\begin{array}{c}\text { Expense } \\
\text { Ratio }\end{array}$ \\
\hline SDS & -2 & ETF & $7 / 13 / 2006$ & $\$ 1,459$ & 105.6 & 8.3 & 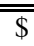 & 13.82 & 0.89 \\
\hline $\mathrm{SH}$ & -1 & ETF & $6 / 19 / 2006$ & $\$ 2,042$ & 58.4 & 2.3 & $\$$ & 34.98 & 0.89 \\
\hline SPXU & -3 & ETF & $6 / 25 / 2009$ & $\$ 727$ & 40.7 & 5.2 & $\$$ & 17.87 & 0.92 \\
\hline SSO & 2 & ETF & $6 / 21 / 2006$ & $\$ 1,832$ & 22.2 & 2.4 & $\$$ & 82.51 & 0.89 \\
\hline UPRO & 3 & ETF & $6 / 25 / 2009$ & $\$ 839$ & 9.1 & 1.6 & $\$$ & 92.15 & 0.95 \\
\hline RSW & -2 & ETF & $11 / 7 / 2007$ & \multirow{2}{*}{\multicolumn{6}{|c|}{ Delisted on $03 / 18 / 2013$}} \\
\hline RSU & 2 & ETF & $11 / 7 / 2007$ & & & & & & \\
\hline SPXS & -3 & ETF & $11 / 5 / 2008$ & $\$ 476$ & 50.4 & 4.2 & $\$$ & 9.43 & 0.95 \\
\hline SPDN & -1 & ETF & $6 / 8 / 2016$ & $\$ 39$ & 2.2 & 0.0 & $\$$ & 17.77 & 0.45 \\
\hline LLSP & 1.25 & ETF & $1 / 7 / 2015$ & $\$ 8$ & 0.3 & 0.0 & $\$$ & 30.26 & 0.35 \\
\hline SPUU & 2 & ETF & $5 / 28 / 2014$ & $\$ 3$ & 0.1 & 0.0 & $\$$ & 40.83 & 0.60 \\
\hline SPXL & 3 & ETF & $11 / 5 / 2008$ & $\$ 552$ & 4.6 & 0.8 & $\$$ & 121.21 & 0.95 \\
\hline BXDD & -3 & ETN & $11 / 17 / 2009$ & \multicolumn{6}{|c|}{ Delisted on $05 / 05 / 2011$} \\
\hline SPLX & 2 & ETN & $3 / 25 / 2014$ & $\$ 6$ & 0.2 & & $\$$ & 40.96 & 0.85 \\
\hline SPDR & 1 & ETF & $1 / 22 / 1993$ & $\$ 230,204$ & 990.1 & 80.9 & $\$$ & 232.51 & 0.09 \\
\hline VOO & 1 & ETF & $9 / 9 / 2010$ & $\$ 63,017$ & 295.2 & 2.0 & $\$$ & 213.47 & 0.05 \\
\hline IVV & 1 & ETF & $5 / 19 / 2000$ & $\$ 102,856$ & 439.5 & 3.7 & $\$$ & 234.03 & 0.04 \\
\hline
\end{tabular}




\section{Table 4 Summary Statistics of Key Variables}

\begin{tabular}{l|rrrrr} 
& Obs & \multicolumn{1}{c}{ Mean } & \multicolumn{1}{c}{ Std. Dev. } & \multicolumn{1}{c}{ Min $^{\mathrm{b}}$} & \multicolumn{1}{c}{ Max $^{\mathrm{b}}$} \\
\hline \hline$\Delta$ & 2,651 & 1.42 & 351.05 & -2870.00 & 2600.00 \\
$\mathrm{r}_{\text {S\&P500 }}{ }^{2}$ & 2,651 & $1.65 \mathrm{E}-04$ & $5.83 \mathrm{E}-04$ & $4.90 \mathrm{E}-11$ & 0.01 \\
$\mathrm{r}_{\text {S\&P500 }}$ & 2,651 & $3.88 \mathrm{E}-04$ & 0.01 & -0.09 & 0.12 \\
Volume & 2,651 & $1.73 \mathrm{E}+08$ & $1.05 \mathrm{E}+08$ & $2.47 \mathrm{E}+07$ & $8.89 \mathrm{E}+08$ \\
\multicolumn{2}{l}{ ' } \\
\multicolumn{2}{l}{ The inception days are excluded } & & &
\end{tabular}

\section{Table 5 Trading Volume Regressed on Rebalancing Demand}

On day $t$, the rebalancing demand is defined as

$\Delta_{\mathrm{t}}=$ Required Exposure - Exposure $=\mathrm{mA}_{\mathrm{t}, \text { close }}-\mathrm{mA}_{\mathrm{t}, \mathrm{open}} \times(1+$ Return $\mathrm{t}, \mathrm{S} \& \mathrm{P} 500)$

with tracking multiple $\mathrm{m}$ and

$\mathrm{A}_{\mathrm{t}, \text { close }}=\mathrm{P}_{\mathrm{t}, \text { close }} \times$ Shares $_{\mathrm{t}+1, \text { open }}$

$A_{t-1, \text { close }}=A_{t, o p e n}=P_{t-1, \text { close }} \times$ Shares $_{t, o p e n}$

The total rebalancing demand is the sum of $\Delta_{\mathrm{t}}$ from lev/inv ETFs based on S\&P 500 index

\begin{tabular}{|c|c|c|c|c|c|c|}
\hline & \multicolumn{6}{|c|}{ Total Daily Trading Volume of SPDR, IVV, and VOO } \\
\hline & \multicolumn{4}{|c|}{ OLS } & IV & IV af \\
\hline $\begin{array}{l}\text { Intercept } \\
\left|\Delta_{t}\right|-\$ \mathrm{~m}\end{array}$ & $\begin{array}{r}1.15 \mathrm{E}+08 * * \\
28,457 * *\end{array}$ & $2.61 \mathrm{E}+07 * * *$ & $2.46 \mathrm{E}+07 * * *$ & $2.53 \mathrm{E}+07 * * *$ & $2.47 \mathrm{E}+07 * * *$ & $2.69 \mathrm{E}+07 * * *$ \\
\hline$\left|\Delta_{t}\right|-$ shares $^{\text {a }}$ & & $6.92 * * *$ & $1.40 *$ & $1.24 *$ & $1.31 *$ & $1.26 *$ \\
\hline$\left|\Delta_{t-1}\right|$ - shares & & & & $0.93 *$ & $-1.83 * *$ & $-1.85 * *$ \\
\hline$\left|\Delta_{\mathrm{t}-2}\right|$ - shares & & & & 0.03 & $1.99 * * *$ & $1.84 * *$ \\
\hline$(\text { Trading Volume })_{\mathrm{t}-1}$ & $0.5818 * *$ & $0.56 * * *$ & $0.53 * * *$ & $0.52 * * *$ & $0.53 * * *$ & $0.53 * * *$ \\
\hline$(\text { Trading Volume })_{\mathrm{t}-2}$ & $0.2341 * *$ & $0.22 * * *$ & $0.20 * * *$ & $0.19 * * *$ & $0.20 * * *$ & $0.20 * * *$ \\
\hline |Index Return| & & & $2.54 \mathrm{E}+09 * * *$ & $2.57 \mathrm{E}+09 * * *$ & $2.84 \mathrm{E}+09 * * *$ & $2.79 \mathrm{E}+09 * * *$ \\
\hline
\end{tabular}

Signif. codes: $* * * 0.001, * * 0.01, * 0.05$

${ }^{a}$ Equivalent shares are calculted as dollar amount of rebalancing demand devided by closing price of SPDR. 
Table 6 SPDR MOC Volume as Proportions of the Total Trading Volume of the Day

\begin{tabular}{|c|c|c|c|c|c|c|c|c|c|c|c|c|c|c|c|c|c|c|}
\hline & \multicolumn{2}{|c|}{2008} & \multicolumn{2}{|c|}{2009} & \multicolumn{2}{|c|}{2010} & \multicolumn{2}{|c|}{2011} & \multicolumn{2}{|c|}{2012} & \multicolumn{2}{|c|}{2013} & \multicolumn{2}{|c|}{2014} & \multicolumn{2}{|c|}{2015} & \multicolumn{2}{|c|}{2016} \\
\hline & $\%$ & $\sigma$ & $\%$ & $\sigma$ & $\%$ & $\sigma$ & $\%$ & $\sigma$ & $\%$ & $\sigma$ & $\%$ & $\sigma$ & $\%$ & $\sigma$ & $\%$ & $\sigma$ & $\%$ & $\sigma$ \\
\hline $15: 00$ & $3.6 \%$ & $1.4 \%$ & $2.8 \%$ & $3.4 \%$ & $3.3 \%$ & $1.8 \%$ & $3.4 \%$ & $1.6 \%$ & $3.6 \%$ & $1.7 \%$ & $4.1 \%$ & $1.8 \%$ & $3.9 \%$ & $1.6 \%$ & $4.7 \%$ & $2.2 \%$ & $4.2 \%$ & $1.9 \%$ \\
\hline $15: 15$ & $3.8 \%$ & $1.2 \%$ & $4.0 \%$ & $2.7 \%$ & $3.7 \%$ & $1.7 \%$ & $4.4 \%$ & $1.6 \%$ & $7.5 \%$ & $4.8 \%$ & $11.8 \%$ & $4.8 \%$ & $10.6 \%$ & $3.9 \%$ & $11.3 \%$ & $5.1 \%$ & $10.5 \%$ & $5.2 \%$ \\
\hline $15: 30$ & $4.7 \%$ & $1.5 \%$ & $3.6 \%$ & $1.5 \%$ & $5.2 \%$ & $2.7 \%$ & $9.4 \%$ & $3.1 \%$ & $6.4 \%$ & $4.5 \%$ & $2.6 \%$ & $1.1 \%$ & $2.7 \%$ & $1.3 \%$ & $2.9 \%$ & $1.0 \%$ & $2.8 \%$ & $1.0 \%$ \\
\hline $15: 45$ & $6.5 \%$ & $2.2 \%$ & $4.7 \%$ & $1.9 \%$ & $8.7 \%$ & $3.8 \%$ & $2.9 \%$ & $1.2 \%$ & $2.8 \%$ & $1.1 \%$ & $2.9 \%$ & $1.1 \%$ & $2.8 \%$ & $1.0 \%$ & $3.2 \%$ & $0.9 \%$ & $4.0 \%$ & $2.9 \%$ \\
\hline Total & $18.6 \%$ & $4.5 \%$ & $15.0 \%$ & $5.8 \%$ & $20.9 \%$ & $6.9 \%$ & $20.1 \%$ & $5.4 \%$ & $20.3 \%$ & $5.9 \%$ & $21.4 \%$ & $6.2 \%$ & $20.0 \%$ & $5.0 \%$ & $22.1 \%$ & $6.7 \%$ & $21.6 \%$ & $5.9 \%$ \\
\hline
\end{tabular}

\begin{tabular}{|c|c|c|c|c|c|c|c|c|c|c|c|c|c|c|c|c|c|c|}
\hline & \multicolumn{2}{|c|}{2008} & \multicolumn{2}{|c|}{2009} & \multicolumn{2}{|c|}{2010} & \multicolumn{2}{|c|}{2011} & \multicolumn{2}{|c|}{2012} & \multicolumn{2}{|c|}{2013} & \multicolumn{2}{|c|}{2014} & \multicolumn{2}{|c|}{2015} & \multicolumn{2}{|c|}{2016} \\
\hline & Sk & Kur & Sk & Kur & 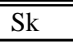 & Kur & Sk & Kur & 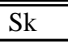 & Kur & 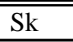 & Kur & "Sk & Kur & Sk & Kur & Sk & Kur \\
\hline $15: 00$ & 1.6 & 7.5 & 1.7 & 6.1 & 2.6 & 14.5 & 1.4 & 5.9 & 1.2 & 4.5 & 1.2 & 4.8 & 0.9 & 3.7 & 1.0 & 4.3 & 1.2 & 5.0 \\
\hline $15: 15$ & 0.8 & 3.3 & 3.5 & 25.8 & 1.1 & 4.8 & 0.8 & 3.9 & 1.7 & 8.0 & 1.0 & 4.3 & 0.8 & 3.8 & 1.0 & 3.8 & 0.8 & 4.9 \\
\hline $15: 30$ & 1.1 & 6.4 & 1.4 & 5.9 & 1.5 & 5.7 & 0.7 & 3.6 & 0.9 & 3.4 & 2.0 & 8.2 & 2.3 & 10.3 & 1.0 & 4.4 & 1.3 & 5.2 \\
\hline $15: 45$ & 1.1 & 4.3 & 1.3 & 5.6 & 0.3 & 2.6 & 2.5 & 13.1 & 2.8 & 20.2 & 2.7 & 16.0 & 1.3 & 5.4 & 1.0 & 5.0 & 2.8 & 10.9 \\
\hline Total & 0.8 & 3.1 & 1.1 & 5.2 & 0.8 & 4.3 & 0.6 & 4.1 & 1.0 & 4.8 & 0.7 & 3.6 & 0.6 & 3.5 & 0.7 & 3.4 & 1.2 & 5.9 \\
\hline
\end{tabular}

Table 7 SPDR MOC Volume Regressed on Rebalancing Demand

\begin{tabular}{|c|c|c|c|c|c|c|c|c|c|c|c|c|c|}
\hline \multirow[b]{2}{*}{ Rebalancing } & \multirow[b]{2}{*}{$\mathrm{t}$} & \multicolumn{2}{|c|}{$\begin{array}{l}\text { Highest } \\
\text { Interval }\end{array}$} & \multicolumn{2}{|c|}{$15: 00$} & \multicolumn{2}{|c|}{$15: 15$} & \multicolumn{2}{|c|}{$15: 30$} & \multicolumn{2}{|c|}{$15: 45$} & \multicolumn{2}{|c|}{ Total } \\
\hline & & 0.33 & **** & 0.27 & **** & 0.19 & **** & 0.28 & **** & 0.28 & *** & 1.10 & **** \\
\hline Demand & $t-1$ & 0.55 & $* * *$ & 0.27 & $* * *$ & 0.20 & $* * *$ & 0.09 & $* * *$ & 0.17 & $* * *$ & 0.81 & $* * *$ \\
\hline Trading & $t-1$ & 0.34 & $* * *$ & 0.37 & $* * *$ & 0.38 & $* * *$ & 0.44 & $* * *$ & 0.47 & $* * *$ & 0.49 & $* * *$ \\
\hline Volume & $\mathrm{t}-2$ & 0.25 & $* * *$ & 0.16 & $* * *$ & 0.26 & $* * *$ & 0.37 & $* * *$ & 0.35 & $* * *$ & 0.21 & $* * *$ \\
\hline Daily Return & $\mathrm{t}$ & $-3 E+04$ & $* *$ & $-7 E+03$ & & $-1 E+04$ & & $-4 E+04$ & & $-5 E+04$ & $*$ & $-1 E+05$ & $* * *$ \\
\hline Intercept & - & 5937 & $* * *$ & 2783 & $* * *$ & 3821 & $* * *$ & 1494 & $* * *$ & 1378 & $* * *$ & 9550 & $* * *$ \\
\hline
\end{tabular}




\section{Table 8 Variance Proxy Regressed on Rebalancing Demand}

On day $\mathrm{t}$, the rebalancing demand is defined as

$\Delta_{\mathrm{t}}=$ Required Exposure - Exposure $=\mathrm{mA}_{\mathrm{t}, \text { close }}-\mathrm{mA}_{\mathrm{t}, \text { open }} \times\left(1+\right.$ Return $\left._{\mathrm{t}, \mathrm{S} \& \mathrm{P} 500}\right)$

with tracking multiple $\mathrm{m}$ and

$\mathrm{A}_{\mathrm{t}, \text { close }}=\mathrm{P}_{\mathrm{t}, \text { close }} \times$ Shares $_{\mathrm{t}+1, \mathrm{open}}$

$A_{t-1, \text { close }}=A_{t, \text { open }}=P_{t-1, \text { close }} \times$ Shares $_{t, \text { open }}$

The total rebalancing demand is the sum of $\Delta_{\mathrm{t}}$ from lev/inv ETFs based on S\&P 500 index

\begin{tabular}{|c|c|c|c|c|c|c|c|c|}
\hline & $\mathrm{r}_{\mathrm{t}, \mathrm{S} \& \mathrm{P} 500}{ }^{2}$ & \multicolumn{7}{|c|}{$\operatorname{Scale}\left(\mathrm{r}_{\mathrm{t}, \mathrm{S} \& \mathrm{P} 500}{ }^{2}\right)^{\mathrm{a}}$} \\
\hline & OLS & \multicolumn{6}{|c|}{ OLS } & $\overline{\mathrm{IV}}$ \\
\hline Intercept & $1.65 \mathrm{E}-04 * * *$ & $0.28 * * *$ & $0.14 * * *$ & $0.14 * * *$ & $0.14 * * *$ & $0.14 * * *$ & $0.14 * * *$ & $0.14 * * *$ \\
\hline$\Delta_{\mathrm{t}}$ & $1.29 \mathrm{E}-07 * * *$ & & & & & & & \\
\hline $\operatorname{Scale}\left(\Delta_{\mathrm{t}}\right)^{\mathrm{a}}$ & & $0.08 * * *$ & $0.10 * * *$ & $0.11 * * *$ & $0.19 * * *$ & $0.19 * * *$ & $0.11 * * *$ & $0.16 * * *$ \\
\hline $\operatorname{Scale}\left(\mathrm{r}_{\mathrm{t}-1, \mathrm{~S} \& \mathrm{P} 500}{ }^{2}\right)$ & & & $0.12 * * *$ & $0.09 * * *$ & $0.12 * * *$ & $0.13 * * *$ & $0.12 * * *$ & $0.11 * * *$ \\
\hline $\operatorname{Scale}\left(\mathrm{r}_{\mathrm{t}-2, \mathrm{~S} \& \mathrm{P} 500}{ }^{2}\right)$ & & & $0.37 * * *$ & $0.34 * * *$ & $0.36 * * *$ & $0.37 * * *$ & $0.37 * * *$ & $0.36 * * *$ \\
\hline $\operatorname{Scale}\left(\mathrm{r}_{\mathrm{t}-3, \mathrm{~S} \& \mathrm{P} 500}{ }^{2}\right)$ & & & & $0.05 * *$ & & & & \\
\hline $\operatorname{Scale}\left(\mathrm{r}_{\mathrm{t}-4, \mathrm{~S} \& \mathrm{P} 500}{ }^{2}\right)$ & & & & $0.11 * * *$ & & & & \\
\hline $\operatorname{Scale}\left(\mathrm{r}_{\mathrm{t}, \mathrm{S} \& \mathrm{P} 500}\right)$ & & & & & $-0.11 * * *$ & $-0.12 * * *$ & & 0.03 \\
\hline $\operatorname{Scale}\left(\Delta_{\mathrm{t}-1}\right)$ & & & & & & $-0.06 * *$ & & $0.10^{* * *}$ \\
\hline $\operatorname{Scale}\left(\Delta_{t+1}\right)$ & & & & & & & $0.04 *$ & \\
\hline
\end{tabular}

Signif. codes: $* * * 0.001, * * 0.01, * 0.05$

$\operatorname{Scale}\left(r^{2}\right)=\frac{r^{2}}{\sigma_{r^{2}}} \quad ; \quad \operatorname{Scale}(\Delta)=\frac{\Delta}{\sigma_{\Delta}}$

\section{Table 9 Variance Proxy Regressed on Rebalancing Demand - Deciles}

Same set of scaled independent variables as in Table 8, IV

Dependent variable is $\operatorname{Scale}\left(\mathrm{r}_{\mathrm{t}, \mathrm{S} \& \mathrm{P} 500}{ }^{2}\right)$, same as Table 8

\begin{tabular}{l|cccccccccc|c}
\hline & \multicolumn{1}{|c}{ Deciles } & \multicolumn{1}{c}{ All Data } \\
\hline \hline$\Delta_{\mathrm{t}}$ & 1 & 2 & 3 & 4 & 5 & 6 & 7 & 8 & 9 & 10 & I0 \\
$\Delta_{\mathrm{t}-1}$ & 0.02 & 0.08 & 0.03 & 0.10 & 0.09 & 0.13 & 0.10 & 0.13 & 0.13 & 0.53 & 0.16 \\
\hline
\end{tabular}

All significant with $\alpha<.05$ 
The Market Impact of Leveraged and Inverse ETFs: Evidence from S\&P 500-Linked Products 24

Table 10 Baseline Variance Decile Distribution Across Years

\begin{tabular}{|c|c|c|c|c|c|c|c|c|c|c|c|}
\hline & 2006 & 2007 & 2008 & 2009 & 2010 & 2011 & 2012 & 2013 & 2014 & 2015 & 2016 \\
\hline \multirow{10}{*}{ 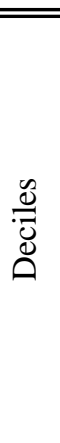 } & $\overline{0}$ & 4 & 25 & 31 & 27 & 29 & 27 & 36 & 29 & 25 & 23 \\
\hline & 0 & 17 & 12 & 23 & 36 & 14 & 24 & 39 & 42 & 21 & 28 \\
\hline & 30 & 32 & 6 & 16 & 31 & 16 & 27 & 15 & 33 & 18 & 31 \\
\hline & 47 & 40 & 8 & 11 & 23 & 21 & 24 & 28 & 19 & 20 & 15 \\
\hline & 21 & 40 & 12 & 9 & 15 & 19 & 23 & 34 & 25 & 25 & 32 \\
\hline & 10 & 22 & 21 & 14 & 17 & 27 & 32 & 30 & 31 & 21 & 31 \\
\hline & 10 & 23 & 29 & 20 & 25 & 20 & 21 & 22 & 17 & 40 & 29 \\
\hline & 6 & 25 & 25 & 27 & 20 & 27 & 32 & 17 & 18 & 34 & 24 \\
\hline & 3 & 21 & 34 & 37 & 24 & 31 & 24 & 17 & 21 & 25 & 19 \\
\hline & 1 & 18 & 72 & 55 & 25 & 40 & 6 & 5 & 8 & 14 & 11 \\
\hline
\end{tabular}


Figure 1 Leveraged and Inverse ETFs Market Share by Index

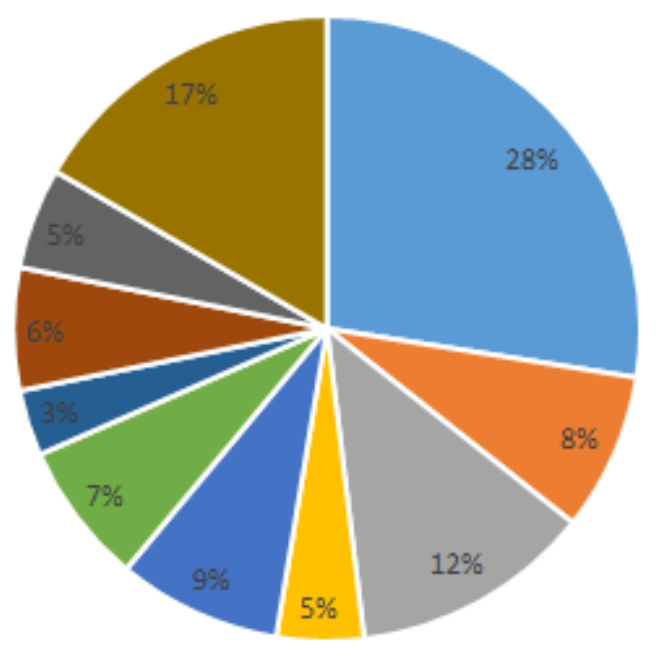

- S\&P 500 INDEX

- RUSSELL 2000 INDEX

= NASDAQ 100 STOCK INDX

= DOW JONES INDUS. AVG

- NYSE Arca Gold Miners Ix

" Russ 1000 Grw TR

- DJ US Financials

- Russ1000 Financial Svc

- MVIS GIJrGoldMiners(TRN)

- ETFs Tracking others Indexes

Based on market capitalization as of February, 2017.

Figure 2 Rebalancing Exposure as Percentage of SPDR Market Cap

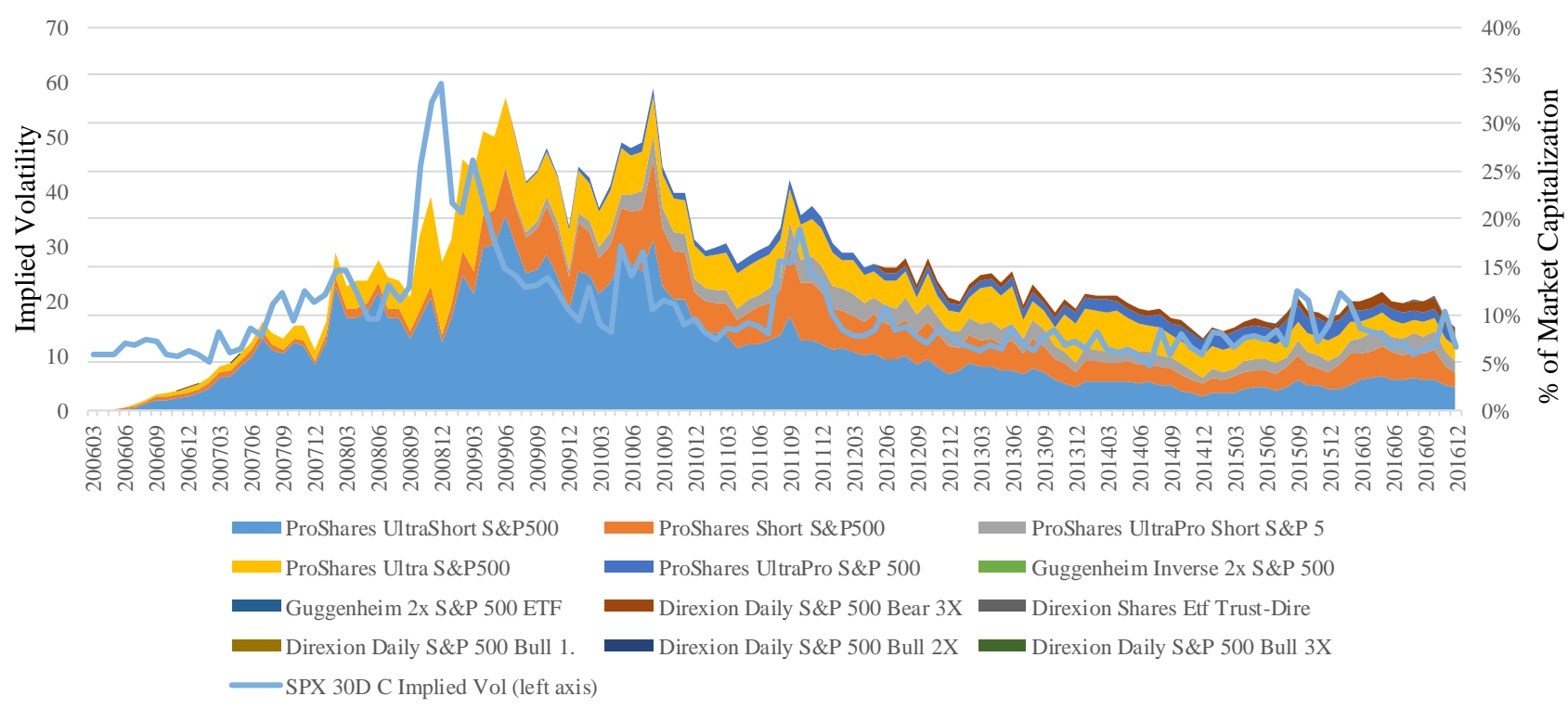


Figure 3 SPDR MOC Trading as Proportion of Total Trading Volume of the Day

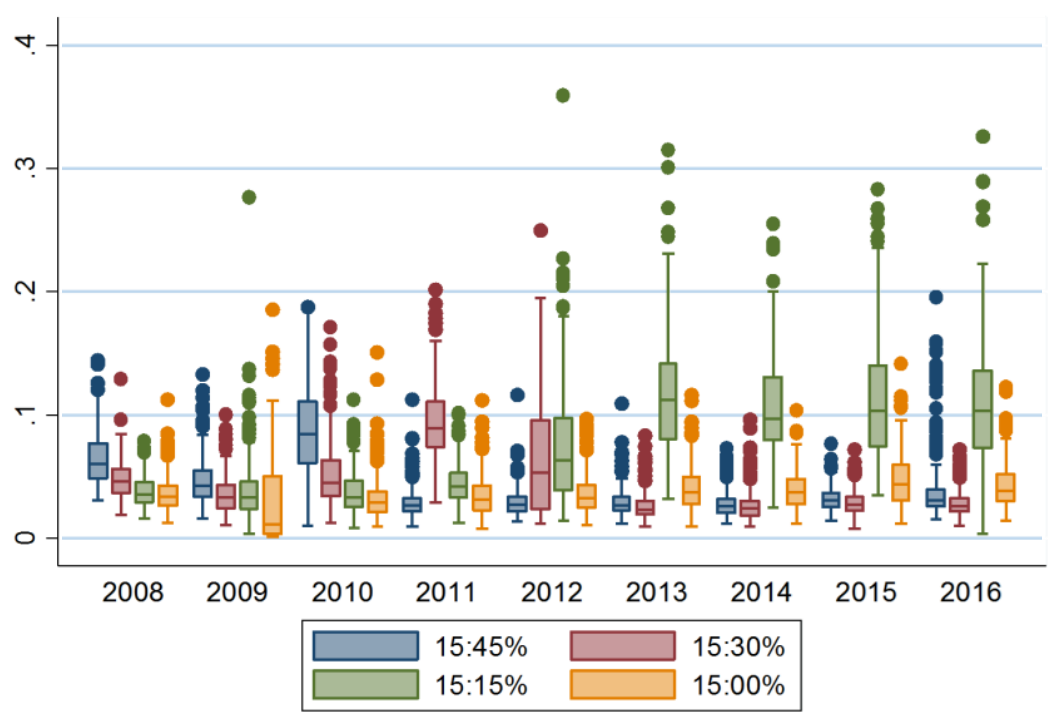

Figure 4 Price of ETFs in 2016

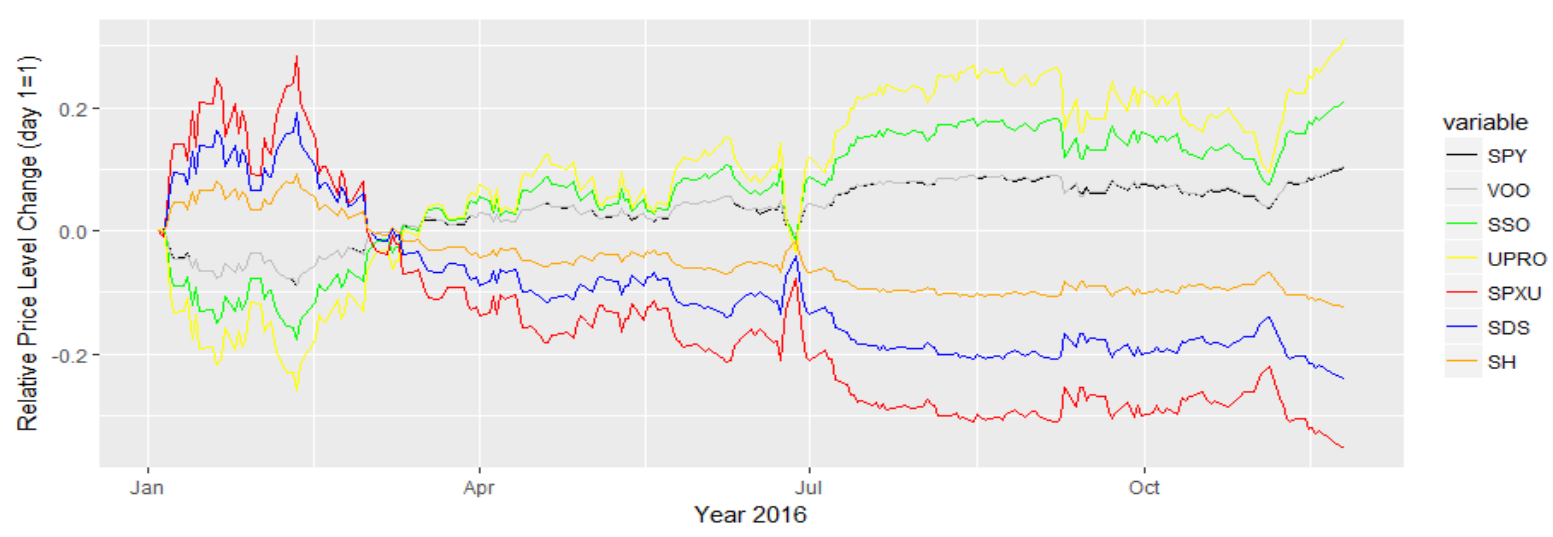




\section{Figure 5 Capital Flows - Significant Impact on Rebalancing Demand}

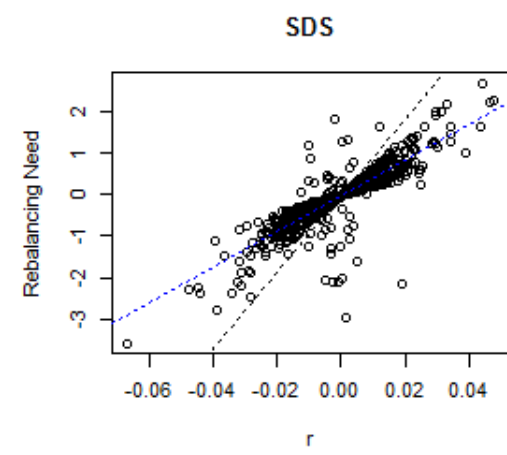

UPRO

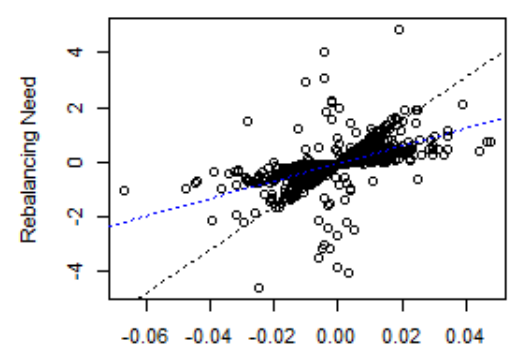

SH

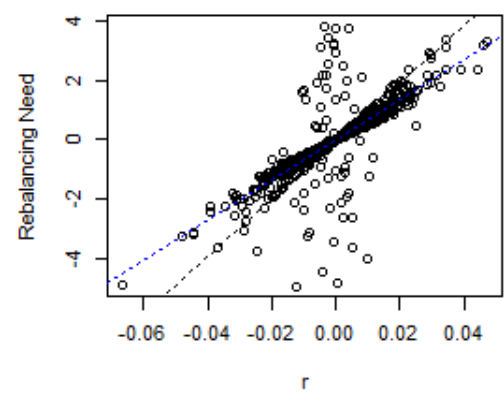

SPXU

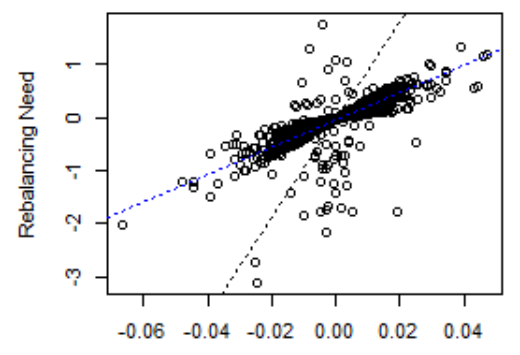

sso

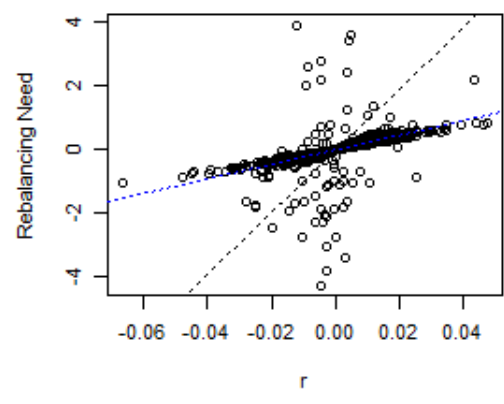

Total

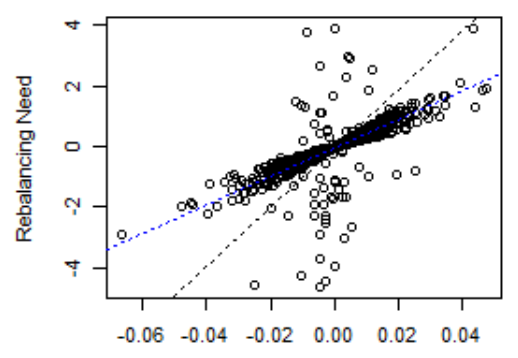

To support the new model adapted from the prior framework of Ivanov and Lenkey (2014), Figure 1 shows how capital flows have mitigated the rebalancing demand of the 5 leveraged or inverse ETFs. While the black line indicates the OLS estimation of rebalancing demand caused by index change in absence of capital flows, the dots indicate the actual rebalancing demand calculated by Equation (1), and the blue line is OLS estimation of rebalancing demand if capital flows happen in the same pattern. Rebalancing demand is in normalized term. Consistent with Ivanov and Lenkey (2014), capital flows tend to mitigate the rebalancing demand caused by index price change. 
The Market Impact of Leveraged and Inverse ETFs: Evidence from S\&P 500-Linked Products 28

\section{References}

Ang, A. (2014). Asset management: A systematic approach to factor investing. Oxford University Press.

Barberis, N., Shleifer, A., \& Wurgler, J. (2005). Comovement. Journal of Financial Economics, 75(2), 283-317.

Bessembinder, H. (2015). Predictable ETF Order Flow and Market Quality. Available at SSRN 2506322.

Ben-David, I., Franzoni, F., \& Moussawi, R. (2014). Do ETFs increase volatility? (No. w20071). National Bureau of Economic Research.

Charupat, N., \& Miu, P. (2011). The pricing and performance of leveraged exchange-traded funds. Journal of Banking \& Finance, 35(4), 966-977.

Cheng, M., \& Madhavan, A. (2009). The dynamics of leveraged and inverse exchange-traded funds. Journal Of Investment Management (JOIM), Fourth Quarter.

Da, Z., \& Shive, S. (2012). Exchange-Traded Funds and Asset Return Correlations. Working paper, University of Notre Dame.

Elton, Edwin J., et al. Spiders: Where are the bugs?. The Journal of Business 75.3 (2002): 453472.

Glosten, L., Nallareddy, S., \& Zou, Y. (2015). ETF Trading and Informational Efficiency of Underlying Securities. Columbia Business School Research Paper.

Hill, J. M., Nadig, D., \& Hougan, M. (2015). A Comprehensive Guide to Exchange-Traded Funds (ETFs). Research Foundation Publications,2015(3), 1-181.

Hasbrouck, Joel. Intraday price formation in US equity index markets. The Journal of Finance 58.6 (2003): 2375-2400. 
Ivanov, I., \& Lenkey, S. (2014). Are Concerns About Leveraged ETFs Overblown. Federal Reserve Board: Finance and Economics Discussion Series, 2106.

Israeli, D., Lee, C., \& Sridharan, S. A. (2015). Is there a dark side to exchange traded funds (ETFs)? An information perspective. Review of Accounting Studies, Forthcoming

Johnson, B., Bioy, H., Choy, J., \& Gabriel, J. (2012). Synthetic ETFs Under the Microscope: A Global Study. Morningstar, 63p. Retrieved from Media. morningstar. com/eu/ETF/assets.

Madhavan, A. (2012). Exchange-traded funds, market structure, and the flash crash. Financial Analysts Journal, 68(4), 20-35.

Ramaswamy, S. (2011). Market structures and systemic risks of exchange-traded funds. Working Paper, Bank for International Settlements.

Understanding synthetic ETFs. Vanguard Research, June 2013.

ETFs: A Call for Greater Transparency and Consistent Regulation. BlackRock, October 2011. 